\title{
Doing and Allowing in the Context of Physician-Assisted Suicide
}

\section{Dieter Birnbacher ${ }^{1}$}

Received: 15 March 2020 / Accepted: 24 March 2020 / Published online: 9 April 2020 (c) The Author(s) 2020

\begin{abstract}
Supporting the (active) rational suicide of a patient with a terminal disease is opposed by a majority of German doctors, whereas assistance in such patients' hastening their death by voluntarily stopping eating and drinking (VSED) is predominantly judged to be acceptable. Are these two positions compatible? It is argued that the normative differentiation cannot be justified by the fact that the assistance in active suicide is itself active, whereas assistance in VSED is merely passive. Even in "letting die" a patient from hastening death by refusing nutrition and hydration there is an active element in the doctor's/the palliative care team's assurance that they will provide palliative support in case of need. Nor can the difference in evaluation be justified by relevant differences in the causal situation. Enabling a patient to perform VSED and assisting a patient's active suicide under the same circumstances are, as far as causal relevance is concerned, on a par. This holds, at least, on a condition view of causality in the tradition of John Stuart Mill. Finally, the paper discusses whether there are other morally relevant dimensions by which actively and passively supporting a patient suicide under the relevant circumstances differ, again with a negative result.
\end{abstract}

\section{A Controversy in Medical Ethics and Medical Law: Assistance in Active Versus Passive Rational Suicide}

For decades, there has been a debate, in medical ethics and medical law, on whether it is legitimate for doctors to assist patients wanting to commit suicide in a final state of their disease, where "suicide" is taken to cover all cases by which a patient intentionally ends his or her life, either actively or by stopping eating and drinking. "Suicide" is commonly understood to cover only cases where someone actively ends his or her own life. Whether cases where a patient voluntarily stops eating and drinking with the intention to hasten his or her death (VSDE) count as cases of suicide, is

Dieter Birnbacher

dieter.birnbacher@hhu.de

1 Institut für Philosophie, Heinrich-Heine-Universität Düsseldorf, 40225 Düsseldorf, Germany 
controversial (cf. Coors et al. 2019). In the following, we presuppose, without further argument, that VSDE should count as (passive) suicide.

Among medical doctors, the majority view is that these two types of cases-aiding active suicide versus aiding passive suicide-differ radically in normative status. The first type of assistance is considered illegitimate, the second legitimate. But are these judgements compatible? Or is there, among these judgements a Wertungswiderspruch (as lawyers say), a valuational inconsistency?

First, three remarks about the terminology used in the following:

1. "Rational suicide" will refer to a suicide committed under four individually necessary and jointly sufficient conditions:

1. The patient is suffering from a condition that is unbearable from his or her point of view and is, with high probability, irreversible.

2. Relevant palliative treatments are either unavailable or are rejected by the patient.

3. The patient consistently, and over a longer period of time, expresses the wish to end his or her life.

4. The patient is fully competent and his or her wish is voluntary and free from pressure or manipulation from others.

This definition is tailored to the present context. There may be other constellations under which a suicide might be classified as rational.

2. As stated above, I will assume that allowing oneself to die is a form of suicide even when it does not involve actively killing oneself. This use deviates from how the concept is commonly understood. It is however, in conformity both with the definitions given by classical authors on suicide such as Schopenhauer ${ }^{1}$ and Durkheim ${ }^{2}$ and with the official definition of the WHO. ${ }^{3}$ It is in conformity, moreover, with the way the expression is commonly used by lawyers. However, subsuming the passive variant under the concept of suicide along with the active variant must not be taken to prejudge their normative status.

3. In talking about allowing oneself to die, the term "allowing", again, will be used as a technical term, implying inaction in relation to the event in question. This is partly in contrast to common usage according to which allowing can under certain circumstances take the form of action, such as with actions of the type "removing barriers" (cf. Persson 2013, 80 ff., Woollard 2015, 62 ff.).

\footnotetext{
1 Schopenhauer discusses suicide by allowing oneself to die in $\S 69$ of his World as Will and Representation by distinguishing between the active or common form (which according him is a manifestation of Will), and the ascetic form, as an example of which he refers to reports on Asian monks starving themselves to death from religious motives.

2 Durkheim's definition reads: "On appelle suicide toute mort qui résulte médiatement ou immédiatement d'un acte positif ou négatif, accompli par la victime elle-même." (Durkheim 1930, 5) "Négatif" obviously refers to acts of omission.

3 "Suicide is an act with a fatal outcome which the deceased, knowing or expecting a fatal outcome, had initiated and carried out with the purpose of provoking the changes he desired" (WHO 1986).
} 
The discrepancy in the normative judgements on actively assisting a rational suicide and passively letting a rational suicide (in the aforementioned sense) take its course can be illustrated by three examples from regulations presently in force in Germany:

1. In criminal law it is widely accepted [and has recently been confirmed by a judgement of the Supreme Court (the BGH)] that a doctor is not required to resuscitate a patient whom he or she knows to have committed rational suicide in the above sense. The same view was taken, as early as 1986, in the Alternativentwurf Sterbehilfe drawn up by a group of lawyers and physicians (Baumann et al. 1986). On the other hand, a new prohibition ( $\$ 217 \mathrm{StGB})$ penalizing suicide assistance under certain circumstances has been added in 2015 to the criminal code. Furthermore, the legal definition of suicide assistance in the relevant law is remarkably inclusive. It prohibits not only providing a lethal chemical, but also giving pertinent information and advice, or giving a patient an opportunity to commit suicide by providing an appropriate room.

2. In the medical code, an explicit prohibition of assisting suicide was introduced in 2011, which, however, is standardly interpreted as prohibiting aiding rational suicide only in its active form. Interestingly, this prohibition has been accepted by a majority but not by all executive medical bodies in Germany, with the result that a physician in one city is under the risk of being sanctioned by his or her Chamber of Physicians whereas a physician in a neighbouring city is not, if these happen to belong to the jurisdiction of different Chambers. The discrepancy in attitudes to assistance in active suicide and tolerating suicide in the passive form of VSED is well documented in a recent statement of the German Society of Palliative Medicine on VSED:

The German Society of Palliative Medicine supports the prohibition expressed in the medical code of a co-operation of doctors in suicide as far as this concerns the prohibition of prescribing substances with the aim of committing suicide as well as the prohibition of giving concrete advice in the planning of a suicide. [...] Voluntary stopping eating and drinking can be an alternative for some patients. To end life in this way, with the possibility of interrupting or abandoning the project at any time, enables these patients to live and die in a self-determined way. (Nauck et al. 2014, 68, 71)

This statement seems provoked by the growing interest of elderly people in VSED triggered by the legal restrictions on physicians' assisting active suicide. Interestingly, it seems to be based on the premise that a "co-operation of doctors in suicide" (where "suicide" is understood as active suicide) is necessarily itself active, whereas a co-operation of doctors with a patient who voluntarily stops eating and drinking, thereby committing suicide in a passive way, is itself passive. The underlying view seems to be that physicians and carers must not be actively involved in initiating the suicidal process and, indirectly, in the patient's death. They are allowed, however, to be tolerant, in cases of rational suicide, of an initiative on the side of the patient 
to end his or her life, either actively or by stopping taking in fluid, as long as this does not involve actively supporting the patient's decision to start the process nor its execution. The only exception is, in the case of VSED, the permission to accompany the process once it has been autonomously started by the patient.

However, if this is the underlying view, it is based on a problematic assumption. The correlation between the descriptive dimensions active and passive and the normative dimensions permissible and impermissible cannot be made as perfect as may seem desirable. The physician tolerating an act of VSED is not only passively involved in the process. Typically, the patient will not start the process without the physician's assurance that he or she will help him or her in a potential crisis during the process. In the cases reported in Chabot's study of a series of Dutch cases, a physician or a palliative care team was not only involved in the process but also involved in the decision to start the process. Chabot strongly recommends this kind of involvement in order to assure the patient and family carers of professional support if the necessity arises (Chabot and Walther 2017, 65).

Though giving this assurance is not strictly a causally necessary condition of the patient's decision to start the process it is typically one of the factors on which this decision depends. Of the cases described in a recent collection of cases, there are only few in which no physician or palliative care team was involved from the start (zur Nieden and zur Nieden 2019, 23). On the other hand, assuring patient and family of accompanying the patient, if the need arises, is a positive act and not merely an act of allowing. The same kind of positive act occurs whenever a hospice, or some other institution, explicitly or implicitly provides patients who declare that they will hasten their death by VSED, with an opportunity to do so. This offer, not unusual in practice, is, again, in many cases a necessary condition of the execution of these patients' wishes. Without the care offered by the hospice, they would not be able to stick to their project, especially if there is nobody else available to care for them during the process.

The reluctance to acknowledge this incompatibility on the part of officials has an obvious motive: to maintain, against appearances, a strict separation between cases in which, on the one hand, a patient is supported in allowing him- or herself to die, either from his or her medical condition, from withholding or withdrawing treatment of this condition, or from passively hastening death, which are held to be ethically acceptable; and supporting, on the other, the patient in actively ending his or her life, which is held to be ethically inacceptable.

\section{Causal Roles}

The normative distinction between allowing and supporting someone to end his or her life passively and allowing and supporting someone to end his or her life actively seems to be deeply engraved in the moral consciousness of physicians, and indeed, in general morality.

Why does the difference between actions of different types but with identical outcomes (the death of the patient) assume such a striking moral importance? 
The point that first comes to mind in thinking about potential justifications is the difference in causal roles. On the (mistaken) assumption that in the case of VSED the attending physician is not actively involved in the process leading to the patient's death, one might reason as follows: As long as there is (1) no positive act of supporting the patient in ending his or her life on the part of physicians and other caregivers, and (2) the act of allowing the patient to die does not constitute an act of actively withdrawing treatment, it might seem that the act of allowing cannot be classified as a causal contribution to hastening the patient's death. This seems to be the case especially when the most salient causal factors are the patient's medical condition and the patient's mentality. On the part of the patient, the same reasoning leads to the conclusion that even the patient is not causally involved in the process leading to his or her death. There is, in VSED, no positive act by which the patient hastens death in the way it is done in a case of (active) suicide. After all, the case is not one of self-killing but of letting him- or herself die. Can one say that the allowing — on the part of the physician or on the part of the patient—contributes to the death of the patient? Can there be such a thing as purely negative causal factor?

This issue has been controversial for a long time, in philosophy as well as in law, and will probably continue to do so. Causality is an abstract concept, with a large variety of functions, and we need intuitive props to give it a concrete meaning. Unfortunately, there is more than one intuitive prop that lends itself to this task, and which of these is preferred depends, to a great extent, on professional background. Scientists, typically, favour what has been called the "productivity view" of causality. One variant of this is the requirement that there must be a flow of energy from the causal factor to the effect or, if not flow of energy, the transference of some other physical magnitude (cf. Fair 1979; Dowe 2000). Obviously, this view is incompatible with including purely negative factors into the causal set.

Lawyers typically replace negative causal factors such as involved in allowing certain processes to take their course by counterfactual constructions, often termed "quasi-causality", denying them causal function without denying responsibility. Thus, in the case of a patient committing suicide, actively or passively, the physician's behaviour in allowing the patient to die would not be held to be a causal factor of the patient's death. However, the physician could nevertheless be held partly responsible for it-given that an intervention on his or her part would, probably or with certainty, have prevented either the suicide attempt or its result, thereby postponing the patient's death. In the case of the patient committing passive suicide, the patient, though not actively involved in it, might nevertheless be held responsible for his or her death. Though, on this view, there is no causality in the strict sense between stopping eating and drinking and death, there still might be "quasi-causality", which is sufficient for the attribution of responsibility.

The background of this interpretation is, again, a productivity view of causality, though, in this case transposed to a hypothetical level: Had the physician positively intervened, this would have produced a result different from what actually came about. Had the patient taken in food and fluid, he or she would not have died earlier than by natural factors.

Another intuitive pathway to the abstract concept of causality is the one that does not link genuine causation to productivity or agency but conceives causality 
as the relation between a certain constellation of conditions and an ensuing event. This alternative picture partly derives from John Stuart Mill. According to this view, causation is a relationship of difference making where effects result from certain constellations of temporally prior conditions without necessarily being produced by them. In this context, difference making serves as an abstract concept that can be spelt out in various ways, on the model of Humean regularity, by a nomological model explaining difference making by causal laws, by a contrafactual model, or on an interventionist model taking its lead from human interventions in the course of nature. Though, on these views, negative items such as omissions and absences cannot produce anything, they may nevertheless enter into difference making relationships with subsequent events by combining with positive factors to form sets of conditions causally sufficient for their effects. Logically, they are on a par with positive causes and fit Mackie's INUS model of causation. Like positive causes they are rarely sufficient and rarely necessary for their effects. Like positive causes, they are "causes" only in the sense of causal factors.

If causes are conceived as sets of conditions rather than producers of their effects, this requires a certain shift in our commonsense view of causal relationships. According to the commonsense view, negative conditions explain certain states of affairs but do not generally cause them alongside with their positive counterparts (cf. Persson 2013, 81). However, this shift is not as radical as it might seem at first sight. For one, causes interpreted as conditions are no less able to fulfil most of the functions of causality in our worldview than the productivity view (cf. Schaffer 2004; Birnbacher and Hommen 2012, 85 ff.):

1. Causality may still play the role of the "cement of the universe" (Mackie 1974). It still may be thought of as the glue of the world, with the only difference that the glue is not made of productivity or transference but of difference making.

2. In epistemic respects, causality still serves as a concept for use in explanation and prognosis. This function is not impaired by the fact that the conception of causation as a productive process is replaced by a conception of difference making. On the contrary, by allowing for negative causal factors along with positive ones, the condition view conforms better with common explanatory practices than its rivals.

3. The justificatory role of causal relations in the attribution of moral and legal responsibility is in no way diminished by conceptualizing causation along the lines of the condition view. On the contrary, it seems better suited to explain the practice of ascribing responsibility for omissions and for negligence than other approaches.

There are further reasons for adopting a condition view of causality. One is adequacy. A condition view leaves room for a myriad of ways of speech we commonly use to express that something is a consequence of something without prejudging whether that something is positive or negative. "Consequence" is the most frequently used term for cause-effect relations with negative causal factors 
such as omissions and absences. There are others which are even closer to expressions carrying connotations of agency and productivity, especially if it is understood that the negative condition is an intentional act. An example is intentional enabling as used in contexts where A enables B to attain something B would not attain unless $\mathrm{A}$ intentionally holds back from attaining it. A relevant example are competitive activities like applying for a position which A will probably obtain if he or she applies for it but deliberately leaves room for someone who A thinks is the more appropriate candidate. In this case, A's inaction might even be said to be productive by enabling $\mathrm{B}$ to start a career. The factor of intention here makes it intuitively easier to see A's inaction as a genuine act and not merely a boundary condition, especially if A's inaction is the crucial condition on which B's opportunity depends.

\section{The Intuitionist Doctrine of Doing and Allowing}

Causality, then, does not do the job of explaining, or even justifying, the normative distinction between doing and allowing, or positive and negative acts. This distinction, however, is one of the pillars of common morality as well as of criminal law. In the case of harms or wrongs, obligations not to do something are commonly easier to justify and to fulfil than obligations not to allow. Hence, permissions to allow are easier to justify than permissions to do. In the case of benefits or goods, obligations to allow are easier to justify than obligations to do, permissions not to do are easier to justify than permissions not to allow.

The most well-known example of the first gradient is the normative distinction commonly made between killing and letting die. Quoting Michael Moore:

I have a strong negative duty not to kill you even though you are a stranger to me; I ... have ... a considerably less stringent duty to prevent your death when compared to my duty not to cause your death. (Moore 2009, 447)

That this distinction is indeed one of the constants of human morality has been confirmed in an international Internet survey by Mark Hauser who found that the doingallowing distinction was one of the central factors in the spontaneous reactions to dilemma cases with identical consequences but different agential patterns such as the well-known trolley cases ultimately going back to the lawyer Engisch (1995, 28). Other central factors were intentionality and instrumentalizing by using a person as a means for the benefit of others (cf. Hauser 2006, $127 \mathrm{ff}$.). Some of these factors may even be hard-wired in the human brain (cf. Greene et al. 2004, 392 ff.).

Criminal law follows the trend of common morality in sanctioning the active doing of legal wrong more severely than the allowing of legal wrong. According to $\S 13$ of the German Penal Code, for example, legal responsibility for negative acts is restricted to cases in which there exists a prior contractual relationship between agent and affected party or in which the agent stands in some form of close relation to the victim. Even then, it makes room for a mitigated punishment.

If the distinct causal roles of doings and allowings are not suited to serve as a basis of the distinction commonly made between their normative status, what else 
can justify this distinction? One way is to introduce it as a self-evident moral intuition in the framework of a deontological ethical theory. Ethical deontologists have less problems with justifying axioms of common-sense morality than have consequentialists. They may resort to the strategy to embed the axiom in their theory by postulating it as a prima-facie principle and explain its inclusion by the overwhelming evidence of moral intuition. For consequentialists, on the other hand, this intuition is one of the most stubborn stumbling blocks for their doctrine, and one frequently quoted reason for rejecting it (cf. e. g. Foot 2002; Gert 1998, 181).

There are reasons to think, however, that consequentialists should not too readily accept this objection. It seems that they have resources to counter the deontological attack and to integrate the complexities of common-sense morality into their outlook. The clue to how this can be done is provided by deontological theories themselves. Far from postulating the "acts and omissions doctrine" (Glover 1977, 92) as an absolute, they are in general prepared to allow exceptions-mirrored, among others, in legal norms that sanction wrongdoing by inaction, either intentionally or negligently, in special cases. Even Thomas Aquinas, often quoted as the first to propose the doctrine in the Christian part of the world, admitted that the principle of the weakening of responsibility for negative acts holds only, in his terminology, "simpliciter et absolute", i.e. prima facie, and can be suspended in individual cases (Thomas Aquinas, Summa theologica, qu.79, art. 49). But on what grounds? This is the crucial question. Is the deontologist able to give reasons for why his prima-facieprinciple loses its force in particular cases?

At this point, the consequentialist is in a clearly better position. Instead of postulating, with reference to widely shared intuitions, auxiliary principles to explain exceptional constellations within the doctrine of acts and omissions, or other primafacie principles to relativize the doctrine, the consequentialist can refer to something more objective, namely to the potential consequences of making a certain principle a rule of social morality. This, at least, is the strategy an adherent of the multi-level scheme of morality proposed by Richard Hare (cf. Hare 1981) would follow. It is clear that this strategy of justification reaches further back in history, to consequentialist thinkers such as Bentham and Mill who treated morality not as an abstract system but as a social tool-indeed the most central of all social tool, and, in consequence, thought it appropriate to subject it, in the first place, to criteria of social efficiency.

\section{4 "Hidden Parameters"}

If there is a moral difference between acts with the same consequences merely by the fact that one act is one of doing whereas the other is one of allowing, the difference, according to consequentialism, can only be based on certain specific characteristics or circumstances of the respective form of acting. Are there such specific characteristics or circumstances?

Of course, there are, and the one that comes to mind first, is the energy an agent has to muster to act instead of remaining inactive or, as Bentham called it, "keeping at rest" (Bentham 1970, 75). Thomas Aquinas seems to refer to this 
difference by asserting that it is easier not to harm than to do good, though he misleadingly changes the example in comparing positive and negative acts. He contrasts harming and not doing good instead of two instances of the same category, i. e. harming by doing and harming by allowing, or else not doing good by allowing and not doing good by doing. Trivially, the consequences of harming (transgressio) are in general worse than the consequences of not doing good (omissio), quite independently of the doing-allowing distinction. Thus, there is only an imperfect correlation between harming and doing and not doing good and allowing. Harm can be done by inaction, and not doing good can be realized by doing.

It is evident that, as far as obligations of non-maleficence are concerned, rules that require positive acts are in general harder to justify than rules that require abstention from negative acts. This is primarily so because positive acts tend to be more demanding. In general, it is more demanding to prevent harm than to refrain from doing harm (cf. Bennett 1995, 143 ff.). The same holds, analogously, for obligations to provide benefits. Helping someone is, in general, more demanding than not hurting him. Obligations to do good are, as a rule, more demanding if they imply action rather than inaction. Conversely, it generally takes more "criminal energy" to actively harm others than to allow that they are harmed by others or by natural forces.

This difference, however, is not universal, and there are a number of exceptions. In some cases, the gradient of demandingness is reversed. Helping B can be easy for A if B is nearby and the means to help B are readily available. Not hurting B can be difficult for A after having been provoked by B.

The demandingness of principles that require positive acts in contrast to principles that require negative acts concern all aspects of human action. Bodily action requires physical and mental acts, mental action mental acts such as attention and will. A modicum of attention is needed even to recognize situations in which intervention is required to prevent harm. Strength of will, and sometimes courage, is needed to take risks by becoming active. Inaction is, as a rule, more comfortable. In many situations, a certain amount of energy is required to overstep the boundaries of one's body and to interfere in the course of things, even if only by word of mouth. One result of studies in bystander invention, which seek explanations for people's passivity in the face of obvious harm, is that preparedness to actively help in emergency cases is highest if there are no other people around. If there are multiple bystanders, each of them tends to explain his or her own inaction by the thought that there may be others around with a higher competence to help the victim. This thought, however, is easily explained as a kind of self-deceit in defence of inertia. Furthermore, actions are less easy to eliminate from one's remembered biography than omissions. In this respect, the expression dirty hands is telling: only action, not inaction, leaves a stain.

Another distinguishing factor is opportunity costs. These are, as a rule, higher for actions than for omissions. The energy required for action might be expended on other activities so that doing frequently implies sacrificing opportunities. This fact is even recognized by archetypical opponents of the doctrine of doing and allowing in the consequentialist camp. Bentham, for example, in a footnote to his Introduction, 
gives the impression that he thinks that positive duties of harm prevention should be held to be morally equivalent to negative duties of not doing harm:

Even forbearance to act, or the negation of motion (that is, of bodily motion) supposes an act done, when such forbearance is voluntary. It supposes, to wit, an act of the will, which is as much a positive act, as much a motion, as any other act of the thinking substance. (Bentham 1970, $97 \mathrm{fn}$.

At the same time, however, Bentham restricts positive duties in proportion to the sacrifice they require by tuning down the demands of morality to the level of mere striving:

If duty means anything, that is, moral duty, it is your duty at least to abstain from it [harm]: and more than that, if it is what lies in your power, and can be done without too great a sacrifice, to endeavour to prevent it. (Bentham 1970, 19f. fn.)

There are many cases in which it is more or less evident that the alternatives to allowing would have worse consequences than the alternatives to doing. In the case of the patient starving him- or herself to death the alternative of fulfilling his or her death-wish by active suicide might require more energy and will-power (e.g. in order to obtain an appropriate substance) or might be experienced as more traumatic by family and friends.

Part of the consequentialist reply to the deontological challenge of the doctrine of doing and allowing is, then, the argument of potential overdemandingness. ${ }^{4}$ The consequentialist is able to justify a differentiation of positive and negative duties to the extent to which the hypothetical equivalence has the tendency to make excessive moral demands. In practice, an equivalence of duties of commission and duties of omission would bear the risk of hyper-moralization, i. e. to be, ultimately, selfdestructive. If we had to feel responsible for all the things that we could actively change to the better, we would be crushed by this responsibility up to a total incapacitation to act. In the real world, responsibility has to be limited if we want to be sure that it will be accepted and followed.

It should be noted that a consequentialist justification on these lines crucially depends on contingent anthropological facts. In a world of fanatical altruists or activists without interest in inertia and self-sufficiency, allowing would probably be felt as no less, or even more, demanding than doing. Active harming might count as less of an evil than it does in the real world, and active well-doing as less praiseworthy. Given that moral principles have to be acceptable in all possible worlds, imaginary worlds like this are a strong argument against any attempt to attribute the normative differentiation between positive and negative acts with the same expected consequences to features intrinsic to these acts.

Besides demandingness, there seems to be another "hidden parameter" of the doing-allowing distinction that is more relevant to permissions than to

\footnotetext{
${ }^{4}$ For the complexities of overdemandingness as an excuse for inaction see Schlothfeldt (2009), $53 \mathrm{ff}$. and van Ackeren and Kühler (2018).
} 
obligations: the perceived threat that might originate from a permission to act rather than from a permission to allow. This threat is an important factor especially if allowing is directed at what seems to be a natural process. Intervening in processes that are seen as natural often meet with a kind of instinctive scepticism that is absent if the same processes are left to the "natural course of events". This tendency sometimes emerges even if allowing can be expected to have more negative consequences than deliberate intervention. This quasi-instinctive tolerance has been called "naturalness bonus" (Birnbacher 2014, 21ff.). Its most conspicuous manifestation is the high degree of tolerance of natural risks even in cases in which these can be prevented by technical means, and the comparatively low degree of tolerance of anthropogenic risks (as, for example, in the case of vaccination). The most telling example is, again, human death. An active contribution to determining the point of time at which death occurs is viewed by many people with a kind of basic distrust even if death is thereby much more peaceful and tolerable for all parties concerned. In contrast, a "natural" death without intervention continues to be idealized in spite of the evidence that a great number of "natural" deaths are far from peaceful (cf. Nuland 1993). There is, furthermore, an analogous asymmetry in the fear of "slippery slopes": Permissions to do are more often the object of slippery slope concerns than permissions to allow. A once given permission for a certain kind of innocuous doing may lead to other kinds of less innocuous doing. Permissions to allow certain processes to proceed are thought to invite slippery slopes (for example by negligence) to a lesser degree.

\section{Consequences for the Practical Issue Under Discussion}

There seem to exist, then, some good consequentialist reasons for a normative differentiation between doings and allowings with the same consequences. The main reason is the tendency of rules requiring the agent to positively act to be more demanding than rules requiring the agent to remain inactive so that a process independent of the agent is allowed to proceed. Another reason is that doing often has higher opportunity costs. It prevents agents from doing other desirable things more than allowings do.

Two things, however, should be noted:

1. The described tendencies are rooted, at least in part, in contingent anthropological facts and not in the intrinsic nature of doings and allowings as such.

2. This tendency is only an overall tendency and does not lend itself to the derivation of rules of a more concrete nature. Even criminal law which is under the obligation to make its norms as explicit as possible cannot do without a certain room of manoeuvre to adapt its sanctions to specific constellations. There are, for example, cases of allowing harm which seem hardly less criminal than their active counterparts, such as deliberately withholding a life-saving medicine from a patient unable to attain it by his or her own efforts. 
With regard to our initial issue, the normative status regulators ascribe to physicians' assistance in their patients' active or passive suicide, the result of our discussion is that the moral differentiation commonly made between supporting an act of active suicide and an act of passive suicide could only be justified if both types of act differ, in one way or other, in the dimensions of demandingness or of potential threat to others. It seems, however, that neither of these dimensions is relevant to the case at hand.

Demandingness, for one, cannot be relevant. Demandingness would be a good reason against an obligation of doctors to actively assist a patient to end his or her life under the relevant circumstances. However, this is not the issue. The issue is not the legitimacy of an obligation, but the legitimacy of a permission. Threat, on the other hand, does not seem to be relevant either. There may be some threat, to some people, in the practice of active euthanasia, as it has become common in the Benelux countries. But this threat relates to the fact that someone else (the physician) functions as an agent and not the patient. It does not allow the conclusion that the same threat is felt in the context of an action controlled by the patient. The only factor that might be felt as a threat is the factor of irreversibility, which is present in active suicide and absent in its passive form. It is improbable, however, that it will make a difference in the situation of rational suicide as defined above.

Of course, there might be, beyond these dimensions, further morally relevant positive or negative consequences that might support the deontological doctrine of doing and allowing. Thus. two questions have to be asked:

1. Is supporting an active suicide, under the conditions specified, potentially more harmful to third parties than supporting a process if VSED?

2. Is supporting an active suicide, under the conditions specified, potentially more beneficial to third parties than supporting a process if VSED?

As to the first question it must be said that rational suicide can indeed cause great harm under the circumstances, especially to family and friends who would prefer the patient to live until life comes to a natural end. This harm has to be borne, however, in both cases alike. On this count, there seems be no relevant difference between the active form and its passive counterpart. For the family, an active suicide under the mentioned conditions may come as a shock, especially if the patient has not adequately communicated his or her project, but VSED can be a strain to them, too. Though there are a number of reports of family members who experience accompanying their relative as deeply rewarding (cf. zur Nieden and zur Nieden 2019), partly because it appears not markedly different from a "natural" death, there are others who find it hard to see the patient gradually decline in physical and mental powers for days or even weeks (Schwarz 2007, 1292). The main burden of the method is, however, on the patient who has to muster up considerable strength of will to suffer the gradual decline and to potentially defend his or her resolution against family members urging the patient to stop the process (cf. Ganzini et al. 2003, 361).

As to the second question, the group with the most significant relative benefit is the group of physicians whose active involvement in the process tends to be 
more limited in the case of the passive form than in the case of the active one, and is easier to reconcile with traditional value orientations. However, for the reasons given above, it is by no means nil, and, no matter whether VSED is classified as a form of suicide or not, the physician making the process possible contributes, in one way or other, to the patient's death. It would, however, be question-begging to argue for the higher acceptability of passive over against active suicide under the relevant conditions with the de facto higher acceptance of the passive variant by physicians. Taken all in all, it must be doubted whether the balance of reasons pro and con establishes a clear priority of the passive over the active variant.

The same can be said of a number of other widespread objections to physicians' assisting patient suicide in terminal conditions which apply to both forms and cannot single out the passive form as less objectionable. This is true, for example, of the risk of misjudging the situation of the patient, or to fail to see that the suicide project in question is not, after all, rational, but that the suicidal person irrationally deprives him- or herself of possibilities of going on living with a satisfactory quality of life. Irrational suicide is in fact harmful, with the harm essentially done to the suicidal person him- or herself. In this way, the majority of suicides is indeed a form of self-harm. This is, however, not the case in the example we have been starting from. That there are criteria by which rational suicides of the kind of our example can be distinguished from the more common run of irrational suicides has been convincingly shown by a number of recent studies (cf. Den Hartogh 2016, 679; Spittler 2017, 417).

My conclusion is that whether suicide is held to be inherently morally problematic (the view of most Catholic moral theologians) or as morally indifferent (the liberal view), there seems to be no moral reason to prefer the passive to the active variant. Neither the deontological "acts and omissions doctrine" nor its consequentialist analogue seem to be able to support this preference.

Acknowledgements Open Access funding provided by Projekt DEAL. The author thanks two anonymous reviewers for a number of valuable comments on the first version of this essay.

\section{Compliance with Ethical Standards}

Conflict of interest The authors declare that they have no conflict of interest.

Open Access This article is licensed under a Creative Commons Attribution 4.0 International License, which permits use, sharing, adaptation, distribution and reproduction in any medium or format, as long as you give appropriate credit to the original author(s) and the source, provide a link to the Creative Commons licence, and indicate if changes were made. The images or other third party material in this article are included in the article's Creative Commons licence, unless indicated otherwise in a credit line to the material. If material is not included in the article's Creative Commons licence and your intended use is not permitted by statutory regulation or exceeds the permitted use, you will need to obtain permission directly from the copyright holder. To view a copy of this licence, visit http://creativecommons.org/licen ses/by/4.0/.

\section{References}

Baumann, J., et al. (1986). Alternativentwurf eines Gesetzes über Sterbehilfe. Stuttgart: Thieme. 
Bennett, J. (1995). The act itself. Oxford: Oxford University Press.

Bentham, J. (1970). An introduction to the principles of morals and legislation (1789). In J. H. Burns \& H. L. A. Hart (Eds.), Collected works (Vol. 1). London: Athlone Press.

Birnbacher, D. (2014). Naturalness. Is the "Natural" preferable to the "Artificial"?. Lanham, MD: University Press of America.

Birnbacher, D., \& Hommen, D. (2012). Negative Kausalität. Berlin: de Gruyter.

Chabot, B., \& Walther, C. (2017). Ausweg am Lebensende (5th ed.). München: Reinhardt.

Coors, M., Simon, A., \& Alt-Epping, B. (Eds.). (2019). Freiwilliger Verzicht auf Nahrung und Flüssigkeit. Medizinische und pflegerische Grundlagen - ethische und rechtliche Bewertungen. Stuttgart: Kohlhammer.

Den Hartogh, G. (2016). Two kinds of suicide. Bioethics, 39(9), 672-680.

Dowe, P. (2000). Physical causation. Cambridge: Cambridge University Press.

Durkheim, É. (1930). Le suicide. Étude de sociologie (1897). Paris: Alcan.

Engisch, K. (1995). Untersuchungen über Vorsatz und Fahrlässigkeit im Strafrecht (1930). Aalen: Scientia.

Fair, D. (1979). Causation and the flow of energy. Erkenntnis, 14, 219-250.

Foot, P. (2002). Killing and letting die. In P. Foot (Ed.), Moral dilemmas and other topics in moral philosophy (pp. 78-87). Oxford: Oxford University Press.

Ganzini, L., et al. (2003). Nurses' experiences with hospice patients who refuse food and fluids to hasten death. New England Journal of Medicine, 394, 359-365.

Gert, B. (1998). Morality. Its nature and justification. New York: Oxford University Press.

Glover, J. (1977). Causing death and saving lives. Harmondsworth: Penguin.

Greene, J. D., et al. (2004). The neural bases of cognitive conflict and control in moral judgment. Neuron, 44, 389-400.

Hare, R. M. (1981). Moral thinking. Its levels, method and point. Oxford: Oxford University Press.

Hauser, M. D. (2006). Moral minds. The nature of right and wrong. New York: Harper.

Mackie, J. L. (1974). The cement of the universe. Oxford: Oxford University Press.

Moore, M. S. (2009). Causation and responsibility. Oxford: Oxford University Press.

Nauck, F., et al. (2014). Ärztlich assistierter Suizid: Hilfe beim Sterben - keine Hilfe zum Sterben. Deutsches Ärzteblatt, 111(3), A67-A71.

Nuland, S. B. (1993). How we die. New York: Knopf.

Persson, I. (2013). From morality to the end of reason. Oxford: Oxford University Press.

Schaffer, J. (2004). Causes need not be physically connected to their effects. The case for negative causation. In C. Hitchcock (Ed.), Contemporary debates in philosophy of science (pp. 197-216). London: Wiley.

Schlothfeldt, S. (2009). Individuelle oder gemeinsame Verpflichtung. Das Problem der Zuständigkeit bei der Behebung gravierender Übel. Paderborn: Mentis.

Spittler, J. F. (2017). Suizidverhütung und Suizidbeihilfe - Unterschiedliche Erfahrungsbereiche. Nervenheilkunde, 36, 416-422.

Schwarz, J. (2007). Exploring the option of voluntarily stopping eating and drinking within the context of a suffering patient's request for a hastened death. Journal of Palliative Medicine, 10(6), 1288-1297.

van Ackeren, M., \& Kühler, M. (Eds.). (2018). The limits of obligation. Abingdon: Routledge.

Woollard, F. (2015). Doing and allowing harm. Oxford: Oxford University Press.

World Health Organization. (1986). Summary report. Working group in preventative practices in suicide and attempted suicide. Copenhagen: WHO Regional Office for Europe.

zur Nieden, C., \& zur Nieden, H.-C. (2019). Umgang mit Sterbefasten. Fälle aus der Praxis. Frankfurt am Main: Mabuse.

Publisher's Note Springer Nature remains neutral with regard to jurisdictional claims in published maps and institutional affiliations. 